\title{
Superior Vena Cava Occlusion
}

National Cancer Institute

\section{Source}

National Cancer Institute. Superior Vena Cava Occlusion. NCI Thesaurus. Code C36065.

Blockage of the lumen of the superior vena cava. 